\title{
Impaired Cerebellar Synaptic Plasticity and Motor Performance in Mice Lacking the mGluR4 Subtype of Metabotropic Glutamate Receptor
}

\author{
Roman Pekhletski, ${ }^{1}$ Robert Gerlai, ${ }^{2}$ Linda S. Overstreet, ${ }^{3}$ Xi-Ping Huang, ${ }^{1}$ Nadia Agopyan, ${ }^{2}$ \\ N. Traverse Slater, ${ }^{3}$ Wanda Abramow-Newerly, ${ }^{2}$ John C. Roder, ${ }^{2}$ and David R. Hampson ${ }^{1}$ \\ ${ }^{1}$ Faculty of Pharmacy and Department of Pharmacology, University of Toronto, and the MRC Group on Nerve Cells and \\ Synapses, Toronto, Ontario, Canada M5S 2S2, ${ }^{2}$ Samuel Lunenfeld Research Institute and the Department of Medical \\ Genetics, University of Toronto, Toronto, Ontario, Canada M5S 2S2, and ${ }^{3}$ Department of Physiology and the \\ Northwestern University Institute for Neuroscience, Northwestern University Medical School, Chicago, Illinois 60611
}

The application of the glutamate analog L-2-amino-4phosphonobutyric acid (L-AP4) to neurons produces a suppression of synaptic transmission. Although L-AP4 is a selective ligand at a subset of metabotropic glutamate receptors (mGluRs), the precise physiological role of the L-AP4-activated mGluRs remains primarily unknown. To provide a better understanding of the function of L-AP4 receptors, we have generated and studied knockout (KO) mice lacking the mGluR4 subtype of mGluR that displays high affinity for L-AP4. The mGluR4 mutant mice displayed normal spontaneous motor activity and were unimpaired on the bar cross test, indicating that disruption of the mGluR4 gene did not cause gross motor abnormalities, impairments of novelty-induced exploratory behaviors, or alterations in fine motor coordination. However, the mutant mice were deficient on the rotating rod motor-learning test, suggesting that mGluR4 KO mice may have an impaired ability to learn complex motor tasks. Patch-clamp and extracellular field re- cordings from Purkinje cells in cerebellar slices demonstrated that L-AP4 had no effect on synaptic responses in the mutant mice, whereas in the wild-type mice $100 \mu \mathrm{M}$ L-AP4 produced a $23 \%$ depression of synaptic responses with an $\mathrm{EC}_{50}$ of $2.5 \mu \mathrm{M}$. An analysis of presynaptic short-term synaptic plasticity at the parallel fiber $\rightarrow$ Purkinje cell synapse demonstrated that pairedpulse facilitation and post-tetanic potentiation were impaired in the mutant mice. In contrast, long-term depression (LTD) was not impaired. These results indicate that an important function of mGluR4 is to provide a presynaptic mechanism for maintaining synaptic efficacy during repetitive activation. The data also suggest that the presence of mGluR4 at the parallel fiber $\rightarrow$ Purkinje cell synapse is required for maintaining normal motor function.

Key words: L-AP4; parallel fiber; post-tetanic potentiation; Purkinje cell; synaptic transmission; gene targeting
The effects of the pharmacological activation of metabotropic glutamate receptors (mGluRs) have been studied extensively for over a decade. The cloning of a family of genes coding for mGluRs has revealed that mGluRs are not homologous with other G-protein-coupled receptors and that they are widely distributed throughout the CNS. Expression of cloned mGluRs in cell lines has demonstrated that the mGluR1 and mGluR5 subtypes of mGluRs are coupled to the stimulation of phosphoinositol turnover, whereas the other members of the mGluR family are coupled to the inhibition of adenylyl cyclase. Additional studies have provided evidence that mGluRs expressed in the CNS are also coupled via G-proteins to the regulation of voltage-gated ion channels (Gerber and Gahwiler, 1994).

The mGluR4, mGluR6, mGluR7, and mGluR8 subtypes of mGluRs (group III mGluRs; Pin and Duvoisin, 1995) are selec-

Received June 14, 1996; revised July 24, 1996; accepted July 26, 1996.

This work was supported by grants from the Medical Research Council of Canada (J.C.R., D.R.H.) and National Institutes of Health (DC02764 to N.T.S.). R.G. was a Medical Research Council CIBA-Geigy Fellow. We thank Drs. S. Alford, A. Baskys, D. Broussard, D. Lodge, M. P. Charlton, P. S. Pennefather, M. B. Robinson, and M. Wojtowizc for helpful discussions, R. J. Wenthold for the mGluR4 antibody, and J. Henderson for histology.

Correspondence should be addressed to Dr. David R. Hampson, Faculty of Pharmacy, University of Toronto, 19 Russell Street, Toronto, Ontario, Canada M5S 2S2.

Copyright (C) 1996 Society for Neuroscience $\quad 0270-6474 / 96 / 166364-10 \$ 05.00 / 0$ tively activated by the synthetic glutamate analog L-2-amino-4phosphonobutyric acid (L-AP4). In the nervous system the application of L-AP4 causes an inhibition of synaptic transmission in several brain regions, including the hippocampus, olfactory tract, spinal cord, and thalamus (Koerner and Johnson, 1992). Data obtained in earlier studies have suggested that L-AP4 produces this effect by the activation of presynaptic glutamate autoreceptors (Koerner and Cotman, 1981; Cotman et al., 1986). Other mGluR agonists such as \pm trans-1-amino-1,3-dicarboxylic acid (trans-ACPD) also inhibit synaptic transmission (Baskys and Malenka, 1991). Because L-AP4 is relatively selective for the mGluR subtypes noted above and trans-ACPD activates a different subset of mGluRs (Schoepp, 1994), the inhibition of synaptic transmission seems to be a common feature of several members of mGluR family.

Expression of the mGluR4 subtype of mGluR in mammalian cell lines has demonstrated that mGluR4 is activated by low micromolar concentrations of L-glutamate and L-AP4 (Tanabe et al., 1993; Eriksen and Thomsen, 1995). In situ hybridization studies have shown that mGluR4 mRNA has a restricted distribution in the mammalian CNS; although moderate levels of mGluR4 mRNA are present in the olfactory bulb and entorhinal cortex, the highest level of expression in both the rat (Tanabe et al., 1993; Prezeau et al., 1994; Saugstad et al., 1994; Ohishi et al., 1995) and human (Flor et al., 1995) CNS is in the granule cells of the 
cerebellum. The axons of the granule cells, which constitute the parallel fiber pathway in the cerebellar cortex, form a glutamatergic synaptic input onto Purkinje cell dendrites; alterations in neurotransmission at the parallel fiber $\rightarrow$ Purkinje cell synapse have been implicated in motor learning (Ito, 1989; Linden, 1994).

Despite the increase in our knowledge of the structure and functions of the cloned receptors expressed in cell lines and of the effects of mGluR agonists and antagonists in the nervous system, the exact biological roles of individual members of the mGluR family in the CNS remain primarily unknown. The inability to ascertain the functions of mGluRs has been caused, in part, by the lack of sufficiently potent and selective pharmacological agents. Thus, the use of alternative strategies for the study of mGluRs is clearly warranted. To address this problem, we have used gene targeting to produce mGluR4 knockout (KO) mice that are devoid of the mGluR4 subtype of mGluR. Because mGluR4 mRNA is highly concentrated in the granule cells of the cerebellum, the mutant mice were assessed in several tests measuring various aspects of motor behavior and at the cellular level by conducting electrophysiological recordings from cerebellar slices.

\section{MATERIALS AND METHODS}

Production of mGluR4 KO mice. An $8.2 \mathrm{~kb}$ Sau3A-HindIII fragment of the mGluR4 gene was isolated from a 129-ES/DASH II mouse genomic library by using a rat cDNA probe. The mouse mGluR4 gene was disrupted by inserting a pgk-1/neo expression cassette into an EcoRV site of the targeted exon; this exon spanned a region encompassing Gly 246-Arg 291 of the putative amino terminal extracellular domain of mGluR4. R1 embryonic stem cells (Nagy et al., 1993) were electroporated with the linearized targeting vector at $500 \mathrm{mF}$ and $250 \mathrm{~V}$. G418 (150 $\mu \mathrm{g} / \mathrm{ml})$ and the pyrimidine analog GANC $(2 \mu \mathrm{M})$ were used for positivenegative selection. Embryonic stem cell colonies (and transgenic mice) were screened by multiple primer PCR (Pekhletski and Hampson, 1996). Cloning and sequencing of the amplified genomic DNA from the positive colonies confirmed the proper genomic targeting site, and Southern blot analyses demonstrated that no secondary random integrations had occurred. One of the targeted embryonic stem cell lines was used for aggregation with CD-1 morulae (Wood et al., 1993). Chimeric male offspring were mated with CD-1 mice to produce heterozygous offspring. All analyses were performed on littermates generated from crosses between heterozygous animals.

Gel electrophoresis and immunoblotting. Gel electrophoresis and immunoblotting of mouse cerebellar samples were conducted as described previously (Hampson et al., 1989); the electrophoresis samples contained $100 \mathrm{~mm}$ dithiothreitol and were not heated before electrophoresis to avoid receptor aggregation. Detection was performed with the enhanced chemiluminescence detection system (Amersham Canada, Toronto, Ontario). Nitrocellulose blots were probed with purified rabbit polyclonal anti-peptide antibodies (kindly provided by R. J. Wenthold) generated against a peptide corresponding to the $\mathrm{C}$ terminus of the mGluR4 sequence (Tanabe et al., 1992). Antibody recognition of mGluR4 was confirmed by immunoblots of recombinant mGluR4 expressed in baculovirus-infected insect cells (data not shown). Affinity-purified antipeptide antibodies that specifically recognized mGluR1 (Hampson et al., 1994), GluR1-4 (Wenthold et al., 1992), GluR6 (Wenthold et al., 1994), and NMDA-R1 (Siegel et al., 1994) also were used for immunoblot analyses.

Behavioral analyses. The behavior of the wild-type $(+/+)$, heterozygous $(+/-)$, and homozygous $(-/-)$ mutant mice was assessed in several tasks, including tests measuring locomotor activity and motor/posture patterns (open field test), fine motor coordination and balance (bar cross), and motor-learning performance (rotating rod motor-learning paradigm). Naive (untrained) mice $(+/+, n=22 ;+/-, n=21 ;-/-, n=24)$ were monitored first for $10 \mathrm{~min}$ in the open field test and subsequently on the bar cross test for another $10 \mathrm{~min}$ at 8 weeks of age, as described (Gerlai et al., 1993). The open field test, which evokes novelty-induced exploratory behavior, consisted of a plastic box $(46 \times 25 \times 15 \mathrm{~cm})$, the bottom of which was covered by a $5 \mathrm{~cm}^{2}$ grid pattern and contained a novel object (plastic bottle). Detailed definitions of the behavioral parameters that were measured are given in van Abeelen (1963), Crusio and van Abeelen (1986), and Gerlai et al. (1993). The bar cross apparatus was an elevated
U-shaped platform with two wider (18 $\mathrm{mm}$ thick) bars and a connecting narrow (1 mm thick) challenge bar. Fine motor coordination was tested for $3 \mathrm{~min}$ by recording the following spontaneously appearing motorposture patterns: falling off, sniffing up, sniffing down, defecating, turning, slipping, crossing, grooming, duration of passivity, and crossing attempts. In the open field test and the bar cross test, motor and posture patterns were recorded with a computer event recorder program (Gerlai and Hogan, 1992).

The rotating rod apparatus (Gerlai et al., 1996) was used to measure the ability of the mice to improve motor performance during repeated exposure to the apparatus. Before the first training session, all mice were habituated to the apparatus by placing them on the rod rotating at 2.5 rpm $(3 \times 2$ min sessions). The training consisted of 21 sessions: three sessions per day with a 90 min intersession interval and three trials per session with $5 \mathrm{sec}$ intertrial intervals. The rotation speed was set initially at $5 \mathrm{rpm}$, and the length of each trial was $30 \mathrm{sec}$ (i.e., the maximum cumulative training duration in a session was $90 \mathrm{sec}$ ). If a mouse stayed on the rotating rod for a total cumulative duration of at least $60 \mathrm{sec}$ during the three trial session, the speed was increased by $2.5 \mathrm{rpm}$ for the next session; if a mouse accumulated $<60 \mathrm{sec}$ on the rod during the three trial session but $>30 \mathrm{sec}$, no speed increase was given. If a mouse could not accumulate $30 \mathrm{sec}$ of on-rod time, the speed was decreased by $2.5 \mathrm{rpm}$ at the next session. The rotation speed the mice were able to master according to these definitions ("learning to" criterion; see Fig. $3 A$ ) was recorded and analyzed statistically. The mice trained in the rotating rod paradigm were given a 5 week resting period and then were retested for a single three trial session on the rod at $30 \mathrm{rpm}$. This test was performed to determine whether performance differences between mutant and wildtype mice were attributable to motor fatigue caused by prolonged exposure to the rotating rod. A separate set of mice $(+/+, n=17 ;+/-, n=$ $16 ;-/-, n=15$ ) that were untrained and had never been exposed to the apparatus were also tested on the rotating rod at $30 \mathrm{rpm}$ (see Fig. $3 B$ ). This test was performed to investigate whether naive mutant mice had a preexisting performance deficit that could be detected only at higher rpm (i.e., more demanding tasks). The results of the rotating rod training were analyzed via a two-way repeated measure ANOVA with factors genotype and session (the repeated factor). All analyses were performed with SYSTAT software (version 5.2, Systat, Evanston, IL).

Electrophysiological recordings. Electrophysiological recordings were conducted on coronal slices prepared from the cerebellar vermis of 2- to 4-week-old mice or Sprague Dawley rats by using a horizontal tissue slicer (vibratome) in ice-cold extracellular solution. Slices were incubated for 1 $\mathrm{hr}$ at $22-24^{\circ} \mathrm{C}$ before recording. For patch-clamp recordings, standard methods for recording from neurons in thin $(150 \mu \mathrm{m}$ thick) slices of cerebellum were used (Rossi et al., 1995). Slices were maintained at $22-24^{\circ} \mathrm{C}$ on the stage of an upright microscope and were perfused continuously by extracellular saline composed of (in $\mathrm{mM}$ ): $126 \mathrm{NaCl}, 3$ $\mathrm{KCl}, 2.5 \mathrm{CaCl}_{2}, 1.5 \mathrm{MgSO}_{4}, 1.0 \mathrm{NaH}_{2} \mathrm{PO}_{4}, 26 \mathrm{NaHCO}_{3}, 16.6$ D-glucose, and 0.01 bicuculline methiodide, gassed with $95 \% \mathrm{O}_{2} / 5 \% \mathrm{CO}_{2}, \mathrm{pH} 7.4$. Patch-clamp pipettes were guided visually to the soma of Purkinje cells. Stimulating electrodes were placed $100-300 \mu \mathrm{m}$ away in the molecular layer to stimulate the parallel fiber tract in the plane of the slice. Data are expressed as mean \pm SEM. For the induction of long-term depression (LTD; Lev-Ram et al., 1995), Purkinje cells were voltage-clamped at -70 $\mathrm{mV}$, and depolarizing command steps (to $0 \mathrm{mV}$ for $100 \mathrm{msec}$ ) were paired with single parallel-fiber stimuli $(100 \mu \mathrm{sec}$ duration delivered $30 \mathrm{msec}$ after the onset of the command step) at $1 \mathrm{~Hz}$ for $30 \mathrm{sec}$. The amplitudes of synaptic currents in a $10 \mathrm{~min}$ period before the induction of LTP were compared with responses over a period of 30-40 min after induction. Single test stimuli (100 $\mu \mathrm{sec}$ duration) were delivered at $20 \mathrm{sec}$ intervals and averaged in 2 min bins.

For extracellular field recordings, $400-\mu \mathrm{m}$-thick coronal slices were placed in an interface chamber and perfused with oxygenated extracellular solution similar to that used in patch-clamp experiments. Extracellular field potentials were evoked by focal stimulation (1-150 mA in amplitude, $50-100 \mu \mathrm{sec}$ in duration) of parallel fibers with a glass pipette filled with $1 \mathrm{M} \mathrm{NaCl}$ and recorded within the same plane, $400 \mu \mathrm{m}$ away from the stimulating electrode. In dose-response studies, L-AP4 (Tocris Cookson, St. Louis, MO) was applied by bath perfusion for $10 \mathrm{~min}$, followed by a $20 \mathrm{~min}$ wash period between doses. In patch-clamp experiments, L-AP4 $(100 \mu \mathrm{M})$ and the putative L-AP4 receptor antagonist (S)-2-amino-2-methyl-4-phosphonobutanoic acid (MAP4, $500 \mu \mathrm{M}$; Tocris Cookson) were applied in the bath for periods of $10-30 \mathrm{~min}$ to assess their effects on the parallel fiber-evoked EPSC. All electrophysiological 
Figure 1. Targeted disruption of the mouse mGluR4 gene. $a$, Schematic representation of mGluR4 gene targeting. Hatched boxes denote the two exons contained within the cloned $8.2 \mathrm{~kb}$ fragment used to construct the targeting vector. The position of the $5^{\prime}$ probe used in Southern blot analyses is shown by an open rectangle. The positions of the primers used in the PCR analyses are indicated by filled triangles. EV, Eco RV; H, HindIII; N, NotI; S, Sau3A; X, $X b a \mathrm{I}$ restriction sites. $b$, Southern blot analysis of the mGluR4 locus in the wild-type $(+/+)$, heterozygous $(+/-)$, and homozygous $(-/-) \mathrm{KO}$ mice. Genomic DNA was digested with $E c o \mathrm{RV}$ and $X b a \mathrm{I}$, separated by electrophoresis, transferred to nitrocellulose, and probed with a ${ }^{32} \mathrm{P}$-labeled 5 ' probe. Arrows indicate the 1.5 and $3.3 \mathrm{~kb}$ fragments of the wild-type and mutant alleles, respectively. $c$, Triple primer PCR differentiating allele combinations of mouse DNA. The wild-type and mutant alleles correspond to the 1068 and $1170 \mathrm{bp}$ bands, respectively. The positions of 3 bands of a $1 \mathrm{~kb}$ ladder (Life Sciences, Hialeah, FL) are indicated in the right lane. $d$, Immunoblot analysis of mouse cerebellar samples using an mGluR4 polyclonal antibody. A prominent $190 \mathrm{kDa}$ immunoreactive form of mGluR4 that is seen in the wild-type and heterozygous mouse cerebellum is absent in the $-/-$ mutant mice.
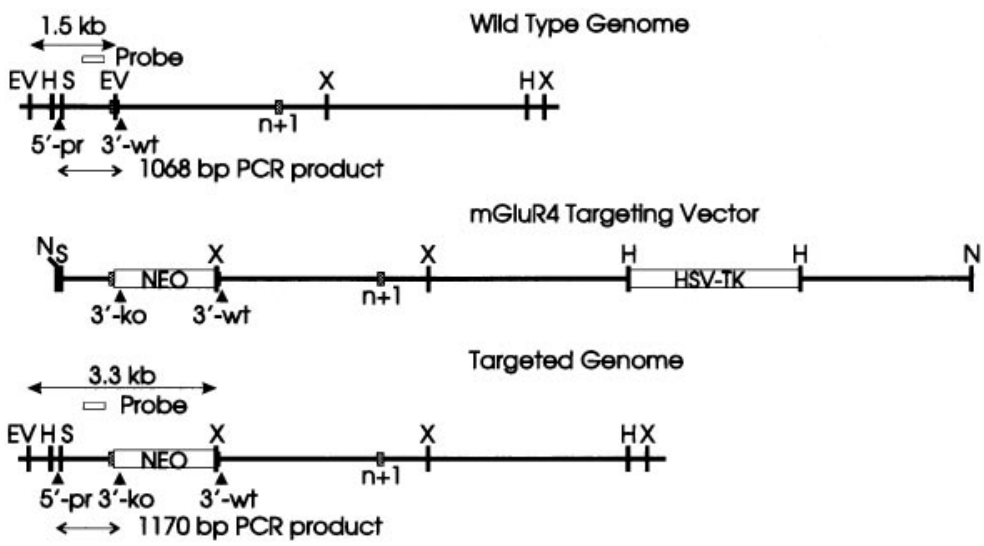

$b$

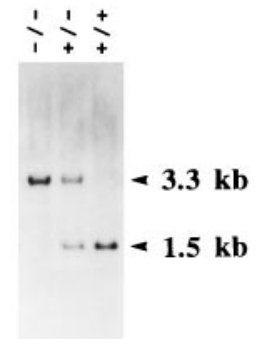

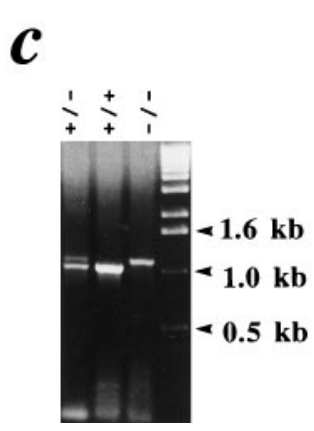

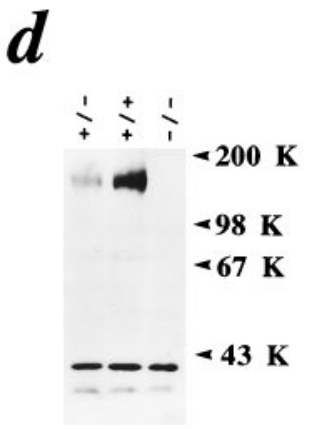

experiments were performed and analyzed without knowledge of the genotype of the animal under investigation.

\section{RESULTS}

\section{Generation and general characterization of mGluR4 KO mice}

mGluR4 knockout mice were generated by disrupting an exon located within the first one-third of the putative extracellular amino terminal domain of the mGluR4 polypeptide (Fig. 1A). Embryonic stem cells were transfected with the targeting vector, and positive clones were identified by a multiple primer PCR strategy (Pekhletski and Hampson, 1996). The frequency of positive colonies was 1 in 31 . One of the mutant embryonic stem cell lines was used to establish chimeric males that were mated with CD-1 mice to produce heterozygous offspring. Southern blot analysis (Fig. $1 B$ ) and multiple primer PCR (Fig. 1C) performed on tail biopsy samples from 438 mice showed that intercrossing of heterozygous mice resulted in the following breakdown by genotype: $+/+,(33 \%)$; $+/-,(43 \%)$, and $-/-,(24 \%)$.

The homozygous mutant mice were indistinguishable from their wild-type littermates in terms of size and gross behavior. An examination of Nissl-stained tissue sections spanning the entire neuraxis of homozygous mutant mice showed no gross abnormalities in cytoarchitecture as compared with unaffected wild-type littermates (data not shown). Immunoblots of cerebella demonstrated that the homozygous $-/-$ mice were devoid of mGluR4 protein, whereas the level of mGluR4 expression in the heterozygous mice was reduced to approximately one-half of the level seen in the wild-type mice (Fig. $1 D$ ). The prominent immunoreactive form of mGluR4 at $190 \mathrm{kDa}$ in the cerebella of wild-type and heterozygous mice was absent in the $-/-$ mutant mice. The relative molecular weight of this form of mGluR4 is approxi- mately double that of the predicted molecular weight, based on the cDNA sequence (Tanabe et al., 1992), suggesting that it may be a dimeric form of the receptor; similar dimeric forms of mGluRs have been reported for mGluR1a and mGluR1b (Pickering et al., 1993; Hampson et al., 1994), mGluR2 (Hayashi et al., 1993), and mGluR3 (Petralia et al., 1996). Although the antibody labeled mGluR4 on immunoblots, cross-reaction with an additional protein in brain tissue of $\sim 40 \mathrm{kDa}$ (Fig. $1 D$ ) precluded the use of this antibody for immunocytochemical studies.

Additional immunoblot analyses of cerebellar samples also indicated that the mutant mice did not differ from their wild-type littermates in the levels of expression of several other glutamate receptors, including the mGluR1a subtype of mGluR, nor were there any differences detected in the levels of expression of ionotropic glutamate receptors, including the GluR1-4 AMPA receptors, the GluR6 kainate receptor, and the NMDA-R1 receptor subunit (Fig. 2).

\section{Behavioral assessments}

No significant differences (univariate and multivariate ANOVA) among the wild-type, heterozygous, and homozygous mice were observed on the open field test or on the bar cross test (Table 1), suggesting that disruption of the mGluR4 gene did not cause gross motor abnormalities, impairments of novelty-induced exploratory behaviors, or alterations of fine motor coordination.

In contrast, the analysis of the performance of the mice on the rotating rod motor-learning paradigm revealed a significant deficit in the $-/-$ mutant mice (Fig. $3 A$ ). These mice were exposed to a 21 session training paradigm during which they were required to cope with an increasingly difficult motor task. Repeated measure ANOVA demonstrated that a significant genotype effect $\left(F_{2,64}=\right.$ $5.617, p=0.006)$, a significant session effect $\left(F_{19,1216}=379.914\right.$, 


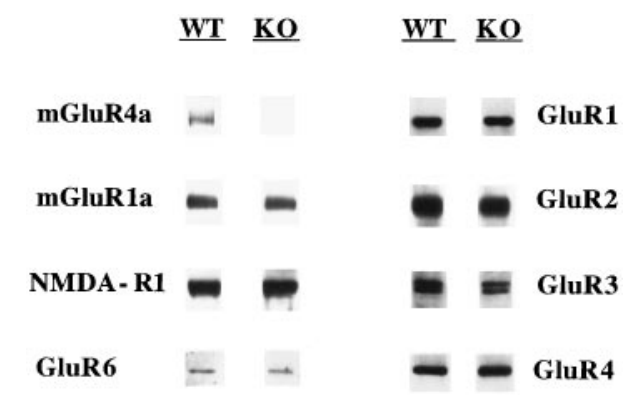

Figure 2. Immunoblot analyses of various glutamate receptors in the cerebella of wild-type and mGluR4 KO mice. All electrophoresis samples contained 25-30 $\mu \mathrm{g}$ of total protein. Except for mGluR4, no differences between the mGluR4 KO mice and wild-type control littermates were observed. Similar results were obtained in samples from two additional wild-type and mutant mice.

$p<0.0001)$, and a significant genotype $\times$ session interaction $\left(F_{38,1216}=4.521, p<0.0001\right)$ were present. Tukey's HSD multiple comparison tests showed no significant phenotypic differences between the mice until the fourteenth session, after which the $-/-$ mice were impaired significantly $(p<0.05)$, as compared with the heterozygous and wild-type mice. These findings indicate that, although all mice improved with training, the improvement rate was significantly lower in the homozygous mutant mice.

The impairment on the rotating rod motor-learning task cannot be attributed to muscle fatigue, because additional experiments demonstrated that the $-/-$ mutant mice were also significantly impaired at a single session administered after a 5 week resting period (mean \pm SEM of latency to fall, in seconds, from the rotating rod in a single session at a speed of $30 \mathrm{rpm}:+/+, 8.8 \pm$ $0.78 ;+/-, 9.9 \pm 1.34 ;-/-, 5.2 \pm 0.76)$. An absence of preexisting motor or sensory defects was indicated further by the lack of significant differences among the genotypes in the falling latency in a separate group of untrained, naive mice tested at $30 \mathrm{rpm}$ (Fig. $3 B)$. The level of difficulty of this task at $30 \mathrm{rpm}$ is comparable to that of the last few sessions in the rotating rod motor-learning paradigm. The lack of abnormal motor/posture patterns on the bar cross, a test for fine motor coordination, also suggests that mGluR4 KO mice do not suffer from an impairment in motor control. Taken together, these observations indicate that the performance deficit of the $-/-$ mutant mice on the rotating rod test may have been attributable to impaired motor learning.

\section{Electrophysiological analyses}

To assess the physiological consequences of the disruption of the mGluR4 gene, we investigated potential alterations in the parallel fiber-evoked excitatory postsynaptic current (EPSC) in mouse cerebellar Purkinje cells. Patch-clamp or field potential recordings from Purkinje cells were obtained in thin cerebellar slices, and the averaged synaptic response evoked by parallel fiber stimulation was examined. In the first series of experiments, the efficacy of L-AP4 in suppressing the synaptic response was studied. In patchclamp experiments, $100 \mu \mathrm{M}$ L-AP4 produced a $22.6 \pm 3.4 \%$ (SEM) depression in the EPSC in the wild-type mice, whereas no depression was observed in the knockout mice (Fig. $4 A-C$ ). This level of inhibition of synaptic transmission was similar to the degree of L-AP4-induced inhibition of $\mathrm{Ca}^{2+}$ currents in cultured olfactory bulb neurons ( $24 \%$ inhibition at $30 \mu \mathrm{M}$; Trombley and Westbrook, 1992). Extracellular field recordings of the parallel fiber-evoked EPSP recorded in the molecular layer of cerebellar vermis showed that L-AP4 produced a dose-dependent inhibition of the synaptic response in the wild-type animals with an $\mathrm{EC}_{50}$ of $2.5 \mu \mathrm{M}$, whereas no significant reduction of the field EPSP by L-AP4 was observed in the $-/-$ animals at concentrations of up to $500 \mu \mathrm{M}$ (Fig. 4D). A modest enhancement of the synaptic re-

\begin{tabular}{|c|c|c|c|c|c|}
\hline Behavior & mGluR4 -/- & MGluR4 +/- & mGluR4 +/+ & $\operatorname{ANOVA}(F)$ & $p$ \\
\hline \multicolumn{6}{|l|}{ Open-field test } \\
\hline Leaning frequency & $27.3 \pm 4.93$ & $26.4 \pm 5.52$ & $20.9 \pm 4.18$ & 0.499 & 0.610 \\
\hline Long-body duration & $4.6 \pm 1.00$ & $4.8 \pm 1.34$ & $6.1 \pm 1.05$ & 0.492 & 0.614 \\
\hline Defecation frequency & $3.3 \pm 0.44$ & $2.2 \pm 0.30$ & $3.3 \pm 0.50$ & 2.113 & 0.129 \\
\hline Urination frequency & $0.5 \pm 0.12$ & $0.6 \pm 0.13$ & $0.6 \pm 0.13$ & 0.100 & 0.905 \\
\hline Grooming duration & $8.1 \pm 0.93$ & $10.2 \pm 2.05$ & $10.6 \pm 1.67$ & 0.748 & 0.477 \\
\hline Locomotion score & $192.9 \pm 28.11$ & $172.0 \pm 24.62$ & $139.5 \pm 22.51$ & 1.141 & 0.326 \\
\hline Object-leaning frequency & $16.9 \pm 3.60$ & $19.0 \pm 2.99$ & $12.5 \pm 1.99$ & 1.163 & 0.319 \\
\hline Passivity duration & $30.8 \pm 4.71$ & $27.5 \pm 5.24$ & $36.6 \pm 4.98$ & 0.824 & 0.443 \\
\hline Rearing frequency & $5.8 \pm 1.78$ & $8.0 \pm 1.81$ & $5.0 \pm 1.56$ & 0.763 & 0.470 \\
\hline Object-sniffing frequency & $12.0 \pm 1.36$ & $9.4 \pm 1.43$ & $9.7 \pm 1.13$ & 1.228 & 0.300 \\
\hline \multicolumn{6}{|l|}{ Bar cross test } \\
\hline Falling frequency & $0.2 \pm 0.10$ & $0.2 \pm 0.14$ & $0.2 \pm 0.11$ & 0.115 & 0.892 \\
\hline Sniffing-up frequency & $9.9 \pm 1.89$ & $9.9 \pm 1.83$ & $9.5 \pm 1.24$ & 0.024 & 0.976 \\
\hline Defecation frequency & $0.9 \pm 0.17$ & $1.0 \pm 0.21$ & $0.9 \pm 0.23$ & 0.133 & 0.875 \\
\hline Turning frequency & $9.3 \pm 1.72$ & $8.6 \pm 1.26$ & $9.7 \pm 1.12$ & 0.165 & 0.848 \\
\hline Slipping frequency & $2.3 \pm 1.35$ & $0.9 \pm 0.30$ & $0.9 \pm 0.20$ & 0.916 & 0.405 \\
\hline Crossing frequency & $1.7 \pm 0.49$ & $1.4 \pm 0.42$ & $1.5 \pm 0.46$ & 0.130 & 0.879 \\
\hline Grooming duration & $2.9 \pm 0.65$ & $3.0 \pm 0.56$ & $4.7 \pm 0.68$ & 2.450 & 0.094 \\
\hline Locomotion duration & $11.6 \pm 1.26$ & $9.1 \pm 1.03$ & $10.0 \pm 1.16$ & 1.238 & 0.297 \\
\hline Passivity duration & $63.4 \pm 4.08$ & $66.4 \pm 3.59$ & $62.7 \pm 2.98$ & 0.277 & 0.759 \\
\hline Sniffing-down frequency & $37.7 \pm 5.73$ & $44.1 \pm 4.90$ & $49.9 \pm 3.72$ & 1.570 & 0.216 \\
\hline Crossing-attempt frequency & $5.8 \pm 1.19$ & $7.3 \pm 1.29$ & $8.1 \pm 1.22$ & 0.976 & 0.382 \\
\hline
\end{tabular}


A

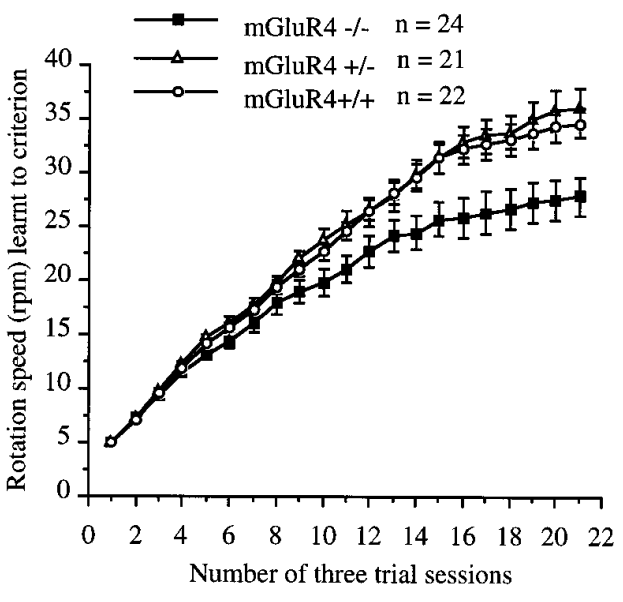

B

mGluR4 - $/-\quad n=15$

mGluR4 $+/-n=16$

$\square$ mGluR4 +/+ $\mathrm{n}=17$

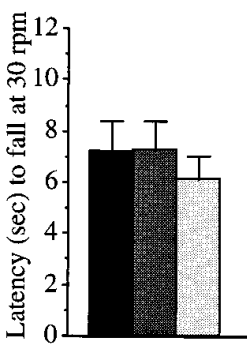

Figure 3. Behavioral analysis of wild-type $+/+$, heterozygous $+/-$, and homozygous $-/-$ mice in the rotating rod motor-learning task. $A$, Motor-learning performance (rotation speed, rpm, "learnt to" criterion) on the rotating rod. The homozygous $-1-$ mutant mice were significantly $(p<$ 0.05 ) impaired, as compared with the $+/+$ and $+/-$ mice from the fourteenth session onward. $B$, Falling latency (in seconds) of naive, untrained mice on the rotating rod at 30 $\mathrm{rpm}$. No significant differences $(p>0.05$, ANOVA) were seen among the $+/+,+/-$, and $-/-$ mice. Values represent the mean \pm SEM.

sponse in both groups was observed at high drug concentrations (Fig. $4 D$ ), which may reflect a weak action of L-AP4 at ACPD-sensitive mGluRs that potentiate the postsynaptic sensitivity of AMPA receptors in Purkinje cells (Glaum et al., 1992). In contrast to the complete lack of effect of L-AP4 in the mutant mice, the KO mice did not differ from their wild-type littermates in their responses to trans-ACPD (10 $\mu \mathrm{M})$, indicating that trans-ACPD-sensitive mGluRs were not altered in mGluR4 KO mice (data not shown).
Figure 4. Effects of L-AP4 on synaptic responses at the parallel fiber $\rightarrow$ Purkinje cell synapse in $+/+$ and $-/-$ mice. Representative patch-clamp recordings from Purkinje cells showing the effects of $100 \mu \mathrm{M} \mathrm{L}-\mathrm{AP} 4$ on wild-type $(A)$ and $-/$ - mutant $(B)$ mice. $C$, L-AP4 $(100 \mu \mathrm{M})$ produced a $22.6 \%$ depression of the parallel fiber-evoked EPSC in the wildtype mice $(n=10)$ but no statistically significant effect in the $-/$ - mutant mice $(n=8)$. $D$, Dose-dependent effects of L-AP4 on extracellularly recorded field EPSPs from wildtype mice (filled circles; $n=10$ ); the $\mathrm{EC}_{50}$ of L-AP4 was 2.5 $\mu \mathrm{M}$. No significant effects of L-AP4 were observed in the $-/-$ mice (open circles; $n=10$ ).

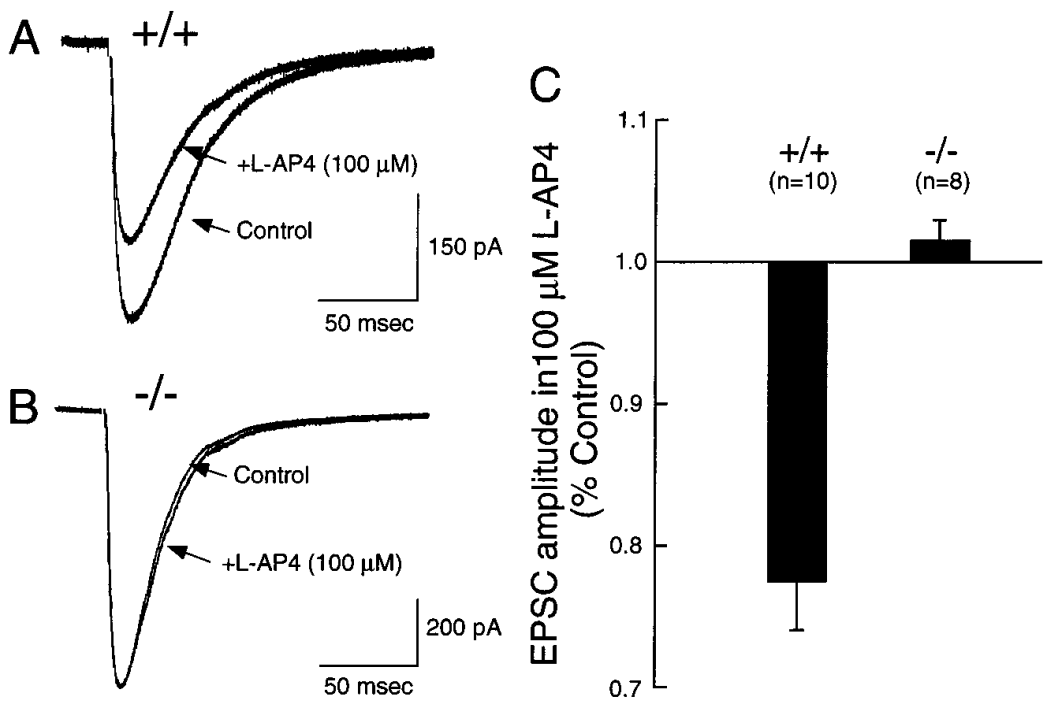

D

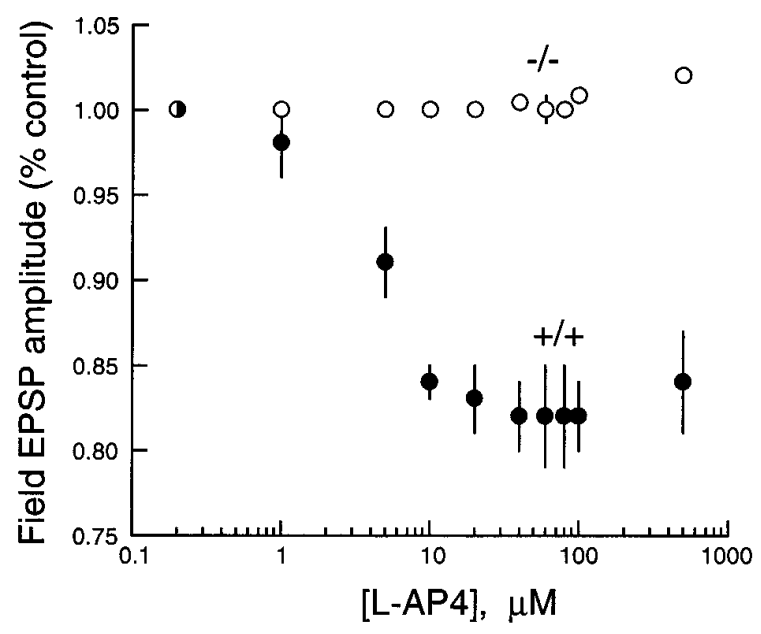



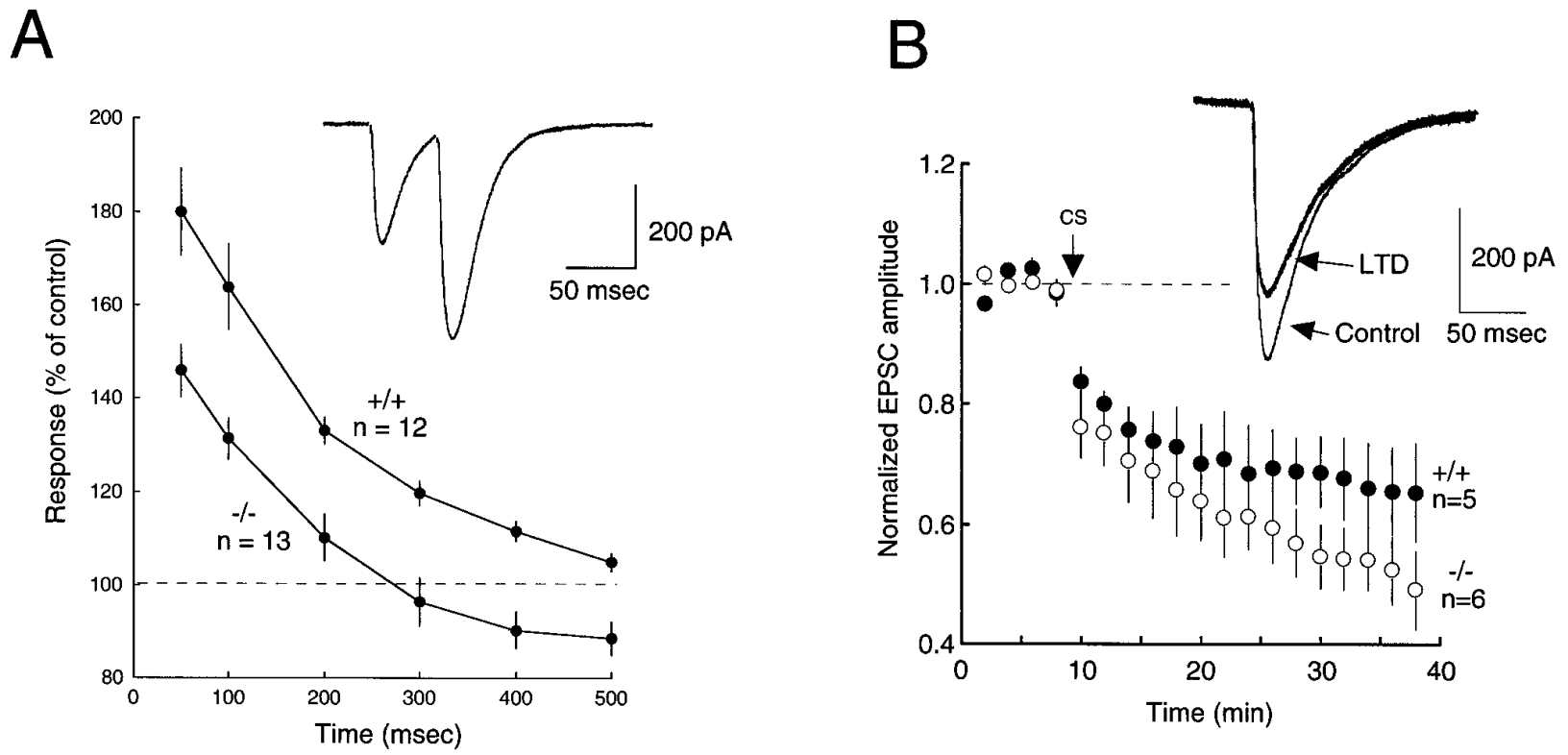

Figure 5. Analysis of short- and long-term synaptic plasticity in cerebellar slices from wild-type $(+/+)$ and mutant $(-/-)$ mice. $A$, Paired-pulse facilitation of parallel fiber-evoked EPSCs in cerebellar Purkinje cells; at each interstimulus interval, the data from the two animals groups displayed a statistically significant difference $(p<0.05$, ANOVA). $B$, Comparison of LTD in wild-type and knockout mice. The degree of depression in the two animal groups was not statistically significant, either when data were compared by trend analysis (repeated-measures ANOVA, $p>0.05$ ) or when the data 30 min after the conditioning stimulus $(C S)$ were examined (ANOVA, $p>0.05$ ). Synaptic currents illustrated in $A$ and $B$ are averaged responses $(n=6)$ to parallel fiber stimulation in Purkinje cells of $+/+$ mice.

Several forms of short- and long-term synaptic plasticity at the parallel fiber $\rightarrow$ Purkinje cell synapse were assessed in thin cerebellar slices from wild-type and $-/-$ mutant mice by using patchclamp recording. To investigate short-term synaptic plasticity, an analysis of paired-pulse facilitation was performed by administering pairs of parallel fiber stimuli at varying interstimulus intervals. In wild-type mice, paired-pulse potentiation was observed at short interstimulus intervals that gradually decayed to control levels after $500 \mathrm{msec}$ (Fig. 5A). This paired-pulse facilitation results both from enhanced presynaptic release and, at short interstimulus intervals $(0-200 \mathrm{msec})$, from a superexcitability period in the parallel fiber axons themselves (Gardner-Medwin, 1972), resulting, in part, from the postsynaptic release of $\mathrm{K}^{+}$(Malenka et al., 1981). The degree of paired-pulse facilitation observed in the homozygous mutant mice was reduced severely, as compared with the wild-type littermates (Fig. 5A). This difference was statistically significant at all interstimulus intervals examined $(p<0.05$, ANOVA). At late $(>300 \mathrm{msec})$ interstimulus intervals, the amplitude of the second EPSC in the wild-type mice was facilitated, whereas in Purkinje cells of mutant mice a depression below baseline values (paired-pulse depression) was observed. These data suggest that the sustained release of L-glutamate from the parallel fiber terminals after single stimuli is sufficient to activate presynaptic mGluR4.

Long-term depression, a cellular model of motor learning (Ito, 1989; Crepel and Jaillard, 1991; Linden, 1994), was produced by conjunctive activation of parallel fibers and a depolarizing postsynaptic voltage step $(-70$ to $0 \mathrm{mV})$. Conjunctive stimulation evoked a robust, long-lasting depression of the EPSC in both animal groups (Fig. 5B). However, despite a modest enhancement of the mean amplitude of the depression in Purkinje cells of $-/-$ mice after conjunctive stimulation, this difference was not statistically significant when assessed $30 \mathrm{~min}$ after the conditioned stimulus $(+/+, 35 \pm$ $8.1 \% ;-/-, 51 \pm 6.7 \%$; repeated measure ANOVA, $p=0.238$; Fig.
$5 B$ ) or by trend analysis of the data throughout the postconditioning period (repeated measures ANOVA, $p>0.05$ ). This finding is in contrast to results obtained in mutant mice lacking the mGluR1 subtype of mGluR in which LTD was severely impaired (Aiba et al., 1994; Conquet et al., 1994).

These results therefore suggest that presynaptic mGluR4 contributes primarily to short-term plasticity of transmission by regulation of presynaptic neurotransmitter release. To investigate this possibility further, we used a burst stimulation paradigm to examine the efficacy of synaptic transmission during and after repetitive stimulation. This stimulus protocol was designed to simulate the expected behavior of parallel fibers during movement in vivo. Mossy fibers are known to fire in high frequency bursts during movement in awake, behaving animals (Bauswein et al., 1984; van Kan et al., 1993), and this will evoke repetitive firing of granule cells that, in turn, will be transmitted to Purkinje cells via the ascending granule cell axon and parallel fibers to produce a temporally summating, AMPA receptormediated EPSP (D'Angelo et al., 1995; Larson-Prior et al., 1995). A train of parallel fiber stimuli was administered, followed by a test stimulus delivered $300 \mathrm{msec}$ after the cessation of the burst, to probe for changes in post-tetanic potentiation (PTP). In wild-type animals, a modest degree of PTP was seen under these conditions in 14 of 24 cells examined, whereas PTP was suppressed dramatically in the -/mGluR4 mutant mice (Fig. 6A,B); the majority of the Purkinje cells in the $-/-$ mice $(24 / 28$ cells) displayed only PTD of the EPSC, similar to that observed in paired-pulse experiments at long $(>300$ $\mathrm{msec}$ ) interstimulus intervals (Fig. 5A). During the burst, the amplitude of the second response was also significantly reduced in -/animals (Fig. 6C). These results further support the notion that mGluR4 functions to conserve presynaptic vesicle stores, thus preventing the more rapid rundown of EPSC amplitude during repetitive synaptic activity and the prolonged reduction of efficiency observed in the mGluR4-deficient mice.

At any given stimulus intensity the absolute amplitude of the 
Figure 6. Post-tetanic potentiation (PTP in Purkinje cells induced by repetitive stimulation of parallel fibers. $A, B$, Responses of Purkinje cells in wild-type $(A ;+/+)$ and mutant $(B ;-/-)$ mice to a stimulus protocol composed of a brief stimulus train (7 stimuli of $100 \mu \mathrm{sec}$ duration at $40 \mathrm{~Hz}$ ), followed by a single test stimulus delivered $300 \mathrm{msec}$ after the burst. To assess the extent of PTP, we compared the amplitude of the synaptic current evoked by the test pulse with that of the first EPSC within the conditioning stimulus train. Synaptic currents in $A$ and $B$ are the averages of six responses to parallel fiber stimulation. $C$, Shown is the mean amplitude of responses within the conditioning burst and the test stimulus in both groups of mice. Asterisks in $C$ indicate that a significant difference (ANOVA, $p<0.05$ ) between cells from wild-type and $-/-$ mutant mice was observed to the second stimulus of the conditioning train and to the PTP test pulse. $D$, Scatterplot of the relationship between the absolute magnitude of the synaptic current (amplitude of the first EPSC in a stimulus train) versus the amount of PTP or posttetanic depression $(P T D)$ observed to the test stimulus (open circles, $+/+$; closed circles, -/-). Dashed lines represent the best fit linear regression line for the two groups.
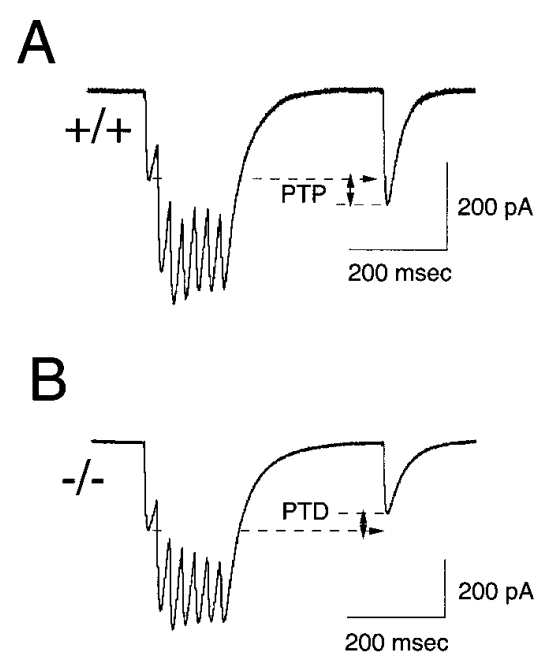
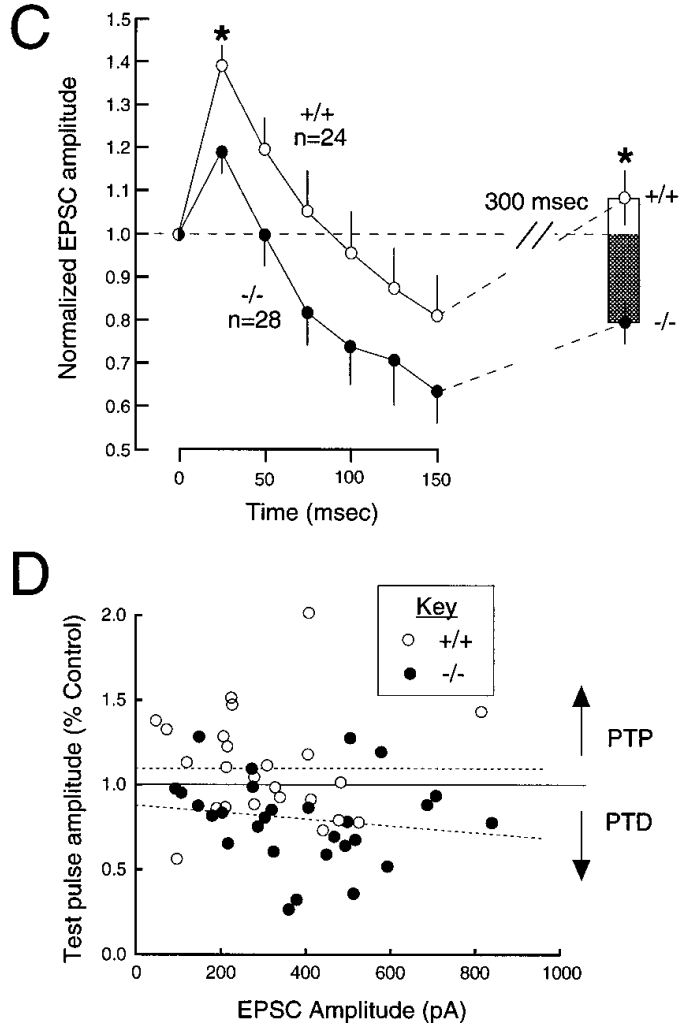

EPSC evoked by parallel fiber stimulation reflects the number of fibers recruited, and some "cross-talk" will occur at individual synapses as glutamate spills over from adjacent terminals to slow glutamate diffusion from the cleft (Barbour et al., 1994; Takahashi et al., 1995). This will result in a prolongation of the lifetime of glutamate in the cleft, which might, in turn, result in an enhanced activation of presynaptic mGluRs. However, in the present experiments no correlation was observed between the amplitude of the first EPSC of a burst and the degree of PTP or PTD observed in either animal group (Fig. 6D).

A pharmacological antagonist with high specificity for mGluR4 in rat brain, the $\alpha$-methyl derivative of L-AP4 (MAP4) recently has been developed (Jane et al., 1994) and examined in several preparations (Bushell et al., 1995; Johansen and Robinson, 1995; Salt and Eaton, 1995). Blockade of presynaptic mGluR4 by MAP4 would be expected to convert PTP to PTD, emulating the behavior of the mGluR4-deficient mouse Purkinje cells during and after repetitive stimulation. However, in experiments with rat Purkinje cells using the same burst stimulus protocol as that in mouse preparations (Fig. $6 A)$, no effects of MAP4 $(500 \mu \mathrm{M})$ were observed on the amplitude of EPSCs during the burst or postburst PTP ( $n=5$; data not shown).

\section{DISCUSSION}

Because of the high concentration of mGluR4 mRNA in the granule cells of the cerebellum, we focused our attention on behavioral experiments designed to assess various aspects of motor function and on synaptic plasticity at the parallel fiber $\rightarrow$ Purkinje cell synapse. The results of the behavioral analyses demonstrated that mGluR4 mutant mice displayed no alterations in motor or posture control in two test situations, the open field test and the bar cross test. The open field test is a sensitive method for revealing motor dysfunction or altered activity levels
(Altman, 1987), whereas the bar cross test measures fine motor coordination (Gerlai et al., 1993). Despite the normal performances on the open field and bar cross tests, the mGluR4 KO mice were impaired significantly on the rotating rod motorlearning task. The absence of deficiencies on the open field and bar cross tests suggests that the impairment on the rotating rod motor-learning task may have been attributable to a decreased ability of the mutant mice to learn the task rather than an impairment in motor control or coordination. Although it is not possible to state conclusively that the impairment on the rotating rod motor-learning task was attributable to a deficiency in motor learning, the suggestion is supported further by the lack of a significant difference between naive, untrained mutant mice and their wild-type littermates on the rotating rod at $30 \mathrm{rpm}$ (Fig. $3 B$ ). The latter observation suggests that a learning (training) phase is required for revealing the deficit on the rotating rod.

The long-term nature of the deficit on the rotating rod motorlearning task was indicated by the finding that the deficit in the trained mice was still apparent after a 5 week resting period. Of interest is the observation that, although the mGluR4 KO mice were clearly impaired on the rotating rod motor-learning task, LTD was not impaired. This finding is in contrast to results obtained with mGluR1 KO mice in which LTD was drastically reduced (Aiba et al., 1994; Conquet et al., 1994). mGluR1 is coupled to phosphoinositol turnover and is expressed postsynaptically at high levels at this synapse in Purkinje cells (Baude et al., 1993; Hampson et al., 1994). Our results indicate that, although the behavioral abnormalities in mGluR4 $\mathrm{KO}$ mice are more subtle than those seen in mGluR1 KO mice, the presynaptic control of glutamate release from parallel fiber terminals (see below) is also a critical factor in motor performance.

The effects of L-AP4 on synaptic transmission in the mamma- 
lian cerebellum have not been reported, although L-AP4 has been shown to inhibit transmission in the turtle cerebellum (LarsonPrior et al., 1990). Our results in wild-type mice indicate that synaptic transmission at the parallel fiber $\rightarrow$ Purkinje cell synapse in mice is highly sensitive to the suppressant effects of L-AP4. Although the maximum degree of suppression of synaptic transmission observed in the cerebellum of wild-type mice (22.6\%; Fig. 4) was modest as compared with that seen in the lateral perforant pathway of the hippocampus (70 $-90 \%$; Koerner and Cotman, 1981), the potency of L-AP4 in the mouse cerebellum $\left(\mathrm{EC}_{50}=2.5\right.$ $\mu \mathrm{M})$ is nearly identical to that reported previously at the perforant path $\rightarrow$ dentate granule cell synapse $\left[\mathrm{EC}_{50}=2 \mu \mathrm{M}\right.$; see Koerner and Johnson (1992) for a discussion of this topic]. The high sensitivity at the parallel fiber $\rightarrow$ Purkinje cell synapse is consistent with the high affinity of mGluR4 for L-AP4 in assays measuring the inhibition of cAMP and radioligand binding in cell lines expressing the cloned receptor (Tanabe et al., 1993; Eriksen and Thomsen, 1995) and with the high level of expression of mGluR4 mRNA in cerebellar granule cells (Tanabe et al., 1993; Ohishi et al., 1995).

The reductions in paired-pulse facilitation and PTP in the mGluR4 KO mice are consistent with previous electrophysiological data and recent immunocytochemical data (Kinoshita et al., 1996; Risso Bradley et al., 1996; Shigemoto et al., 1996) indicating a presynaptic locus for L-AP4 receptors. Data from previous electrophysiological studies have suggested that L-AP4 acts as an agonist at presynaptic autoreceptors to inhibit glutamate release (Koerner and Cotman, 1981; Mayer and Westbrook, 1987; Gereau and Conn, 1995). In the paired-pulse facilitation paradigm, the amplitude of the second response increases relative to the first response, although the absolute amplitude of both the first and second responses is reduced. The enhancement or facilitation of the second response has been attributed to residual calcium present in the presynaptic nerve terminal after the first pulse. In the presence of presynaptic inhibitors, such as L-AP4, the percentage of the increase in the second response is augmented (Koerner and Johnson, 1992). Thus our observation demonstrating a reduction in paired-pulse facilitation in mGluR4 $\mathrm{KO}$ mice is consistent with the effects of L-AP4 in the normal rodent CNS. We hypothesize that, at synapses where mGluR4 is present, activation of the receptor by synaptically released glutamate reduces the probability of further release, thus conserving the number of neurotransmitter vesicles available for a second or subsequent stimuli. In the absence of mGluR4, the release probability is increased during the first pulse, and the amplitude of subsequent stimuli is reduced because of a reduction in the number of available vesicles. Thus, the depressed synaptic responses seen in the mGluR4 KO mice may have been caused by a depletion of neurotransmitter as a consequence of the absence of mGluR4 receptors that act as presynaptic autoreceptors to limit neurotransmitter release.

The reduction in PTP observed in mGluR4 knockout mice is similar to the decrease in PTP reported for mice lacking synapsin II (Rosahl et al., 1995), a synaptic vesicle protein involved in the exocytosis of neurotransmitter stores from nerve terminals. The results obtained from the synapsin II-deficient mice suggested that synapsin II was required for accelerating synaptic vesicle trafficking during and after repetitive synaptic activity. Our results show that mGluR4, like synapsin II, contributes to the ability of the presynaptic nerve terminal to sustain sufficiently high levels of neurotransmitter release during periods of intense synaptic activity. The relatively high potency of glutamate for competing with $\left[{ }^{3} \mathrm{H}\right] \mathrm{L}-\mathrm{AP} 4$ binding to cloned mGluR4 $\left(\mathrm{IC}_{50}=1.6 \mu \mathrm{M}\right.$; Eriksen and Thomsen, 1995), combined with the similar potency data of L-AP4 in suppressing synaptic transmission in cerebellar slices from wild-type mice $\left(\mathrm{EC}_{50}=2.5 \mu \mathrm{M}\right.$; Fig. $\left.4 D\right)$, suggests that mGluR4 may be activated early in the course of heightened synaptic activity. Our results showing differences in the wild-type and mGluR4 mutant mice in the amplitudes of the EPSCs during repetitive stimulation (Fig. 6) suggest that activation of mGluR4 by synaptically released glutamate may occur on a very rapid time scale. Alternatively, mGluR4 might be activated tonically at resting glutamate levels in the absence of repetitive stimulation. The tonic activation of mGluR4 may provide an explanation for the rapidity of the changes observed in the amplitude of the EPSC during the burst.

The restricted distribution of mGluR4 in the CNS, combined with the high level of expression of mGluR4 mRNA in the granule cells of the cerebellum, strengthens our suggestion that the motor deficit revealed in the motor-learning task is a consequence of the impairment in short-term, presynaptic synaptic plasticity at the parallel fiber $\rightarrow$ Purkinje cell synapse. The issue as to whether the cerebellum serves as a site of information storage in motor learning or participates primarily as an integrator of motor and sensory information, with long-term storage taking place at other brain sites, is part of an ongoing debate (Bloedel et al., 1991). In the latter view, the output of Purkinje cells would encode frequency components required for associative long-term storage at postsynaptic sites. The present results with mGluR4 KO mice provide an example of an impairment in motor learning when short-term plasticity mediated by presynaptic mGluRs at parallel fiber terminals is disrupted, but without a concomitant reduction of LTD. Because mGluR4 is highly localized to this single synapse within motor pathways, the data support a role for mGluR4 in the integration of afferent input and subsequent sculpting of Purkinje cell output required for motor learning.

The molecular mechanism of L-AP4-mediated suppression of synaptic transmission is not known. Several other neurotransmitter receptors that are negatively coupled to adenylyl cyclase in cell lines also inhibit transmitter release in the nervous system, suggesting a common pathway. The low micromolar potency of L-AP4 on synaptic transmission that we observed in cerebellar slices from wild-type mice is similar to the potency for inhibiting forskolin-stimulated cAMP formation in cultures of cerebellar granule cells (Prezeau et al., 1994), suggesting a possible link between the two effects of L-AP4 in the cerebellum. The mGluR/ G-protein-mediated inhibition of presynaptic calcium channels is another potential mechanism for explaining the inhibitory effects of L-AP4. Using cultured olfactory neurons, Trombley and Westbrook (1992) showed that L-AP4 had minimal effects on calcium currents at $1 \mu \mathrm{M}$, and maximal inhibitory effects were observed at $30 \mu \mathrm{M}$. Both the dose-response profile and the maximum level of inhibition $(23.6 \%)$ are nearly identical to those that we observed for the inhibition of synaptic transmission in the mouse cerebellum (Fig. 4C,D). Nevertheless, despite these interesting observations, the determination of the mechanism of L-AP4 effects will require further study. The availability of mGluR4-deficient mice may prove to be a valuable tool both for elucidating the molecular mechanisms underlying L-AP4 receptors and for clarifying the biological roles of mGluR4 in the nervous system.

\section{REFERENCES}

Aiba A, Kano M, Chen C, Stanton ME, Fox GD, Herrup K, Zwingman TA, Tonegawa S (1994) Deficient cerebellar long-term depression and impaired motor learning in mGluR1 mutant mice. Cell 79:377-378. 
Altman J (1987) Morphological and behavioral markers of environmentally induced retardation of brain development: an animal model. Environ Health Perspect 74:153-168.

Barbour B, Keller BU, Llano I, Marty A (1994) Prolonged presence of glutamate during excitatory synaptic transmission to cerebellar Purkinje cells. Neuron 12:1331-1343.

Bauswein E, Kolb FP, Rubia FJ (1984) Cerebellar feedback signals of a passive hand movement in the awake monkey. Pflügers Arch 402:292-299.

Baskys A, Malenka RC (1991) Agonists at metabotropic glutamate receptors presynaptically inhibit EPSCs in neonatal rat hippocampus. J Physiol (Lond) 444:687-701.

Baude A, Nusser Z, Roberts JDB, Mulvihill E, McIlhinney RAJ, Somogyi $P$ (1993) The metabotropic glutamate receptor (mGluR1a) is concentrated at perisynaptic membrane of neuronal subpopulations as detected by immunogold reaction. Neuron 11:771-787.

Bloedel JR, Bracha V, Kelly TM, Wu J-Z (1991) Substrates for motor learning. Does the cerebellum do it all? Ann NY Acad Sci 627:305-318.

Bushell TJ, Jane DE, Tse H-W, Watkins JC, Davies CH, Garthwaite J, Collingridge GL (1995) Antagonism of the synaptic depressant actions of L-AP4 in the lateral perforant path by MAP4. Neuropharmacology 34:239-241.

Conquet F, Bashir ZI, Davies CH, Daniel H, Ferraguti F, Bordi F, Franz-Bacon K, Reggiani A, Martarese V, Conde F, Collingridge GL, Crepel F (1994) Motor deficit and impairment of synaptic plasticity in mice lacking mGluR1. Nature 372:237-244.

Cotman CW, Flatman JA, Ganong AH, Perkins MN (1986) Effects of excitatory amino acid antagonists on evoked and spontaneous excitatory potentials in guinea pig hippocampus. J Physiol (Lond) 378:403-415.

Crepel F, Jaillard DJ (1991) Pairing of pre- and postsynaptic activities in cerebellar Purkinje cells induces long-term changes in synaptic efficacy in vitro. J Physiol (Lond) 432:123-141.

Crusio WE, Abeelen JHF (1986) The genetic architecture of behavioral responses to novelty in mice. Heredity 56:55-63.

D’Angelo E, De Filippi G, Rossi P, Taglietti V (1995) Synaptic excitation of individual rat cerebellar granule cells in situ: evidence for the role of NMDA receptors. J Physiol (Lond) 484:397-413.

Eriksen L, Thomsen C (1995) [ $\left.{ }^{3} \mathrm{H}\right]$-L-2-amino-4-phosphonobutyrate labels a metabotropic glutamate receptor, mGluR4a. Br J Pharmacol 116:3279-3287.

Flor PJ, Lukic S, Ruegg D, Leonhardt T, Knopfel T, Kuhn R (1995) Molecular cloning, functional expression, and pharmacological characterization of the human metabotropic glutamate receptor type 4 . Neuropharmacology 34:149-155.

Gardner-Medwin AR (1972) An extreme supernormal period in cerebellar parallel fibers. J Physiol (Lond) 222:357-371.

Gerber U, Gahwiler BH (1994) Modulation of ionic currents by metabotropic glutamate receptors. In: The metabotropic glutamate receptors (Conn PJ, Patel J, eds), pp 125-146. Totowa, NJ: Humana.

Gereau RW, Conn PJ (1995) Multiple presynaptic metabotropic glutamate receptors modulate excitatory and inhibitory synaptic transmission in hippocampal area CA1. J Neurosci 15:6879-6889.

Gerlai R, Hogan JA (1992) Learning to find the opponent: an ethological analysis of the behavior of paradise fish (Macropodus opercularis) in intra- and interspecific encounters. J Comp Psychol 106:306-315.

Gerlai R, Friend W, Becker L, O'Hanlon D, Marks A, Roder JC (1993) Female transgenic mice carrying multiple copies of the human gene for S100B are hyperactive. Behav Brain Res 55:51-59.

Gerlai R, Millen KJ, Herrup K, Joyner AL, Roder JC (1996) Impaired motor-learning performance in cerebellar En-2 mutant mice. Behav Neurosci 110:126-133.

Glaum SR, Slater NT, Rossi DJ, Miller RJ (1992) Role of metabotropic glutamate (ACPD) receptors at the parallel fiber-Purkinje cell synapse. J Neurophysiol 68:1453-1462.

Hampson DR, Wheaton KD, Dechesne CJ, Wenthold RJ (1989) Identification and characterization of the ligand-binding subunit of a kainic acid receptor using monoclonal antibodies and peptide mapping. J Biol Chem 264:13329-13335.

Hampson DR, Theriault E, Huang X-P, Kristensen P, Pickering DS, Frank JE, Mulvihill E (1994) Characterization of two alternatively spliced forms of a metabotropic glutamate receptor in the central nervous system of the rat. Neuroscience 60:325-336.

Hayashi Y, Momiyama A, Takahashi T, Ohishi H, Ogawa-Meguro R, Shigemoto R, Mizuno N, Nakanishi S (1993) Role of a metabotropic glutamate receptor in the synaptic modulation in the accessory olfactory bulb. Nature 366:687-689.

Ito M (1989) Long-term depression. Annu Rev Neurosci 12:85-102.

Jane DE, Jones PLStJ, Pook PC-K, Tse H-W, Watkins JC (1994) Actions of two new antagonists showing selectivity for different subtypes of metabotropic glutamate receptor in the neonatal rat spinal cord. $\mathrm{Br} \mathrm{J}$ Pharmacol 112:809-816.

Johansen PA, Robinson MB (1995) Identification of 2-amino-2-methyl4-phosphonobutanoic acid as an antagonist at the mGluR4a receptor. Eur J Pharmacol 290:R1-R3.

Kinoshita A, Ohishi H, Nomura S, Shigemoto R, Nakanishi S, Mizuno N (1996) Presynaptic localization of a metabotropic glutamate receptor, mGluR4a, in the cerebellar cortex: a light and electron microscopic study of the rat. Neurosci Lett 207:199-202.

Koerner JF, Cotman CW (1981) Micromolar L-2-amino-4-phosphonobutyric acid selectively inhibits perforant path synapses from the lateral entorhinal cortex. Brain Res 216:192-198.

Koerner JF, Johnson RL (1992) L-AP4 receptor ligands. In: Excitatory amino acid receptors: design of agonists and antagonists (KrogsgaardLarsen P, Hansen JJ, eds), pp 308-330. London: Ellis Horwood.

Larson-Prior LJ, McCrimmon DR, Slater NT (1990) Slow excitatory amino acid receptor-mediated synaptic transmission in turtle cerebellar Purkinje cells. J Neurophysiol 63:637-650.

Larson-Prior LJ, Morrison PD, Bushey RM, Slater NT (1995) Frequency-dependent activation of a slow $N$-methyl-D-aspartatedependent excitatory postsynaptic potential in turtle cerebellum by mossy fibre afferents. Neuroscience 67:867-879.

Lev-Ram V, Makinds LR, Keitz PF, Kao JPY, Tsien RY (1995) Longterm depression in cerebellar Purkinje neurons results from coincidence of nitric oxide and depolarization-induced $\mathrm{Ca}$ transients. Neuron 15:407-415.

Linden DJ (1994) Long-term synaptic depression in the mammalian brain. Neuron 12:457-472.

Malenka RC, Kocsis JD, Ransom BR, Waxman SG (1981) Modulation of parallel fiber excitability by postsynaptically mediated changes in extracellular potassium. Science 214:339-341.

Mayer ML, Westbrook GL (1987) The physiology of excitatory amino acids in the vertebrate central nervous system. Prog Neurobiol 28:197-276.

Nagy A, Rossant J, Nagy R, Abramow-Newerly W, Roder JC (1993) Derivation of completely cell culture-derived mice from early-passage embryonic stem cells. Proc Natl Acad Sci USA 90:8424-8428.

Ohishi H, Akazawa C, Shigemoto R, Nakanishi S, Mizuno N (1995) Distributions of the mRNAs for L-2-amino-4-phosphonobutyratesensitive metabotropic glutamate receptors, mGluR4 and mGluR7, in the rat brain. J Comp Neurol 360:555-570.

Pekhletski R, Hampson DR (1996) Differentiating allele combinations of a transgene using multiple primer PCR. Biotechniques 20:956-960.

Petralia RS, Wang Y-X, Niedzielski AS, Wenthold RJ (1996) The metabotropic glutamate receptors $\mathrm{mGluR} 2$ and mGluR3 show unique postsynaptic and presynaptic and glial localizations. Neuroscience 71:949-976.

Pickering DS, Thomsen C, Suzdak PD, Fletcher EJ, Robitaille R, Salter MW, MacDonald JF, Huang X-P, Hampson DR (1993) A comparison of two alternatively spliced forms of a metabotropic glutamate receptor coupled to phosphoinositol turnover. J Neurochem 61:85-92.

Pin J-P, Duvoisin R (1995) The metabotropic glutamate receptors: structure and function. Neuropharmacology 34:1-26.

Prezeau L, Carrette J, Helpap B, Curry K, Pin J-P, Bockaert J (1994) Pharmacological characterization of metabotropic glutamate receptors in several types of brain cells in primary culture. Mol Pharmacol 45:570-577.

Rosahl TW, Spillane D, Missler M, Herz JR, Selig DK, Wolff JR, Hammer RE, Malenka RC, Südhof TC (1995) Essential functions of synapsins I and II in synaptic vesicle regulation. Nature 375:488-493.

Risso Bradley S, Levey AI, Hersch SM, Conn PJ (1996) Immunocytochemical localization of group III metabotropic glutamate receptors in the hippocampus with subtype-specific antibodies. J Neurosci 16:2044-2056.

Rossi DJ, Alford S, Mugnaini E, Slater NT (1995) Properties of transmission at a giant glutamatergic synapse in cerebellum: the mossy fiber-unipolar brush cell synapse. J Neurophysiol 74:24-42.

Salt TE, Eaton SA (1995) Distinct presynaptic metabotropic receptors for L-AP4 and CCG1 on GABAergic terminals: pharmacological evi- 
dence using novel $\alpha$-methyl derivative mGluR antagonists, MAP4 and $\mathrm{MCCG}$, in the rat thalamus in vivo. Neuroscience 65:5-13.

Saugstad JA, Kinzie JM, Mulvihill ER, Segerson TP, Westbrook GL (1994) Cloning and expression of a new member of the L-amino-4phosphonobutyric acid-sensitive class of metabotropic glutamate receptors. Mol Pharmacol 45:367-3772.

Schoepp DD (1994) Pharmacological properties of metabotropic glutamate receptors. In: The metabotropic glutamate receptors (Conn PJ, Patel J, eds), pp 31-58. Totowa, NJ: Humana.

Siegel SJ, Brose N, Janssen WG, Gasic GP, Jahn R, Heinemann SF, Morrison JH (1994) Regional, cellular, and ultrastructural distribution of $N$-methyl-D-aspartate receptor subunit 1 in monkey hippocampus. Proc Natl Acad Sci USA 91:564-568.

Shigemoto R, Kulik A, Roberts JDB, Ohishi H, Nusser Z, Kaneko T, Somogyi P (1996) Target cell-specific concentration of a metabotropic glutamate receptor in the presynaptic active zone. Nature 381:523-525.

Takahashi M, Kovalchuk Y, Attwell D (1995) Pre- and postsynaptic determinants of EPSC waveform at cerebellar climbing fiber and parallel fiber to Purkinje cell synapses. J Neurosci 15:5693-5702.

Tanabe Y, Masu M, Ishii T, Shigemoto R, Nakanishi S (1992) A family of metabotropic glutamate receptors. Neuron 8:169-179.

Tanabe Y, Nomura A, Masu M, Shigemoto R, Mizuno N, Nakanishi S
(1993) Signal transduction, pharmacological properties, and expression patterns of two rat metabotropic glutamate receptors, mGluR3 and mGluR4. J Neurosci 13:1372-1378.

Trombley PQ, Westbrook GL (1992) L-AP4 inhibits calcium currents and synaptic transmission via G-protein-coupled glutamate receptor. J Neurosci 12:2043-2050.

van Abeelen JHF (1963) Mouse mutants studied by means of ethological methods. I. Ethogram. Genetika 34:79-94.

van Kan PLE, Gibson AR, Houk JC (1993) Movement-related inputs to intermediate cerebellum of the monkey. J Neurophysiol 69:74-94.

Wenthold RJ, Yokotani N, Doi K, Wada K (1992) Immunochemical characterization of the non-NMDA glutamate receptor subunit-specific antibodies: evidence for a hetero-oligomeric structure in rat brain. J Biol Chem 267:501-507.

Wenthold RJ, Trumpy VA, Zhu WS, Petralia RS (1994) Biochemical and assembly properties of GluR6 and KA2, two members of the kainate receptor family determined with subunit-specific antibodies. J Biol Chem 269:1332-1339.

Wood SA, Allen ND, Rossant J, Auerbach A, Nagy A (1993) Noninjection methods for the production of embryonic stem cell-embryo chimaeras. Nature 365:87-89. 